\title{
Fragilidade fiscal e os ciclos econômicos no Brasil pós-Plano Real: evidências de um modelo de fator dinâmico associado à análise VAR
}

Fiscal fragility and business cycles in Brazil after the Real Plan: evidence from a dynamic factor model applied to VAR analysis

\author{
Bruno Alves Moura (1) \\ Gisele Ferreira Tiryaki(2) \\ Diego Nunes Teixeira ${ }^{(3)}$ \\ (1) Universität Siegen, Siegen \\ (2) Universidade Federal da Bahia \\ ${ }^{(3)}$ Universidade Federal da Bahia
}

\begin{abstract}
Fiscal policy interventions are frequently prescribed to attenuate fluctuations in economic activity. Reliance on fiscal initiatives is particularly recommended during severe recessions when monetary policy has limited efficacy. Nevertheless, empirical evidence from emerging economies indicates that public expenditures frequently exhibit a procyclical behavior, and fiscal imbalances may trigger economic crises. This paper applies a dynamic factor model to derive an index of the public sector financial fragility and estimates vector autoregressions (VAR) to investigate the cyclical behavior of fiscal policy in Brazil. Using monthly data from 1996 to 2019, the empirical analysis verified if fiscal fragility grows as the country's economic activity expands. The results show that fiscal fragility apparently declines after positive exogenous shocks in production and other factors that contribute to macroeconomic instability lead to greater fiscal imbalances, such as increases in exchange rate volatility.
\end{abstract}

\section{Keywords}

fragility, public finance, business cycles.

JEL Codes E32, E62, C32.

\section{Resumo}

Iniciativas de política fiscal são comumente indicadas para amenizar as flutuações na atividade econômica, particularmente durante recessões severas, quando a política monetária torna-se menos eficaz. No entanto, a evidência empírica em países emergentes mostra que os gastos públicos exibem frequentemente um comportamento pró-cíclico e os desequilibrios fiscais podem desencadear crises econômicas. Este trabalho tem por objetivo utilizar o modelo de fator dinâmico para construir um indice de fragilidade fiscal que permita analisar o comportamento cíclico da política fiscal no Brasil por meio de modelos de vetores autorregressivos (VAR). Utilizando dados mensais entre 1996 e 2019, a análise empírica verificou se as finanças públicas no Brasil se deterioram durante expansões na atividade econômica. Os resultados indicam que choques exógenos na produção aparentam reduzir a fragilidade fiscal e outros fatores que promovem a instabilidade macroeconômica contribuem para a deterioração das finanças públicas, como uma maior volatilidade cambial.

\section{Palavras-chave}

fragilidade, finanças públicas, ciclos econômicos.

Códigos JEL E32, E62, C32. 


\section{Introdução}

A ênfase na política fiscal como elemento estabilizador dos ciclos econômicos deu-se particularmente a partir de Keynes (1992). Defendia-se que uma elevação dos investimentos públicos durante recessões estimularia a demanda agregada e minimizaria perdas com o desemprego e o declínio da produção. Esse comportamento contracíclico da política fiscal ${ }^{1}$ não deveria acarretar desequilíbrios fiscais permanentes, pois as intervenções deveriam ser preventivas, com recursos públicos reservados para tal fim (Ferrari Filho; Terra, 2012). Não obstante, a fragilização das contas públicas durante recessões seria uma possibilidade concreta na ausência de planejamento governamental de longo prazo ou de financiamento sustentável para déficits públicos.

Após a Grande Depressão, muitos governos adotaram essa conduta na crença que intervenções de política monetária não seriam eficazes em situações de severa contração na produção e taxas de juros nominais próximas a zero (Boianovsky, 2004). A partir da década de 1970, no entanto, ceticismo na eficácia da política fiscal voltou a ser dominante. Entre os argumentos utilizados para defender o uso de política monetária em detrimento da política fiscal destacam-se os efeitos significativamente defasados da política fiscal, o comportamento forward-looking dos consumidores tornando as iniciativas fiscais inócuas e a falta de confiança nas motivações dos políticos.

A demora das economias em retomar suas trajetórias de crescimento após a crise de 2008 trouxe as discussões sobre o papel estabilizador da política fiscal novamente ao debate econômico (Ramey, 2011; Auerbach, 2012; Akerlof et al., 2014). Nos países emergentes, no entanto, o uso ativo de iniciativas fiscais ainda é controverso, pois desequilíbrios fiscais são comumente identificados como elementos desencadeadores ou amplificadores de crises financeiras. Flutuações na disponibilidade de crédito para o governo e problemas de agenciamento de caráter político tornariam as políticas fiscais pró-cíclicas, com déficits fiscais e a fragilidade das finanças públicas aumentando durante expansões na atividade econômica.

1 As expressões política fiscal "contracíclica" ou "pró-cíclica" são utilizadas para ilustrar o comportamento dos gastos públicos e da fragilidade fiscal nos ciclos econômicos. A política fiscal é contracíclica quando os gastos públicos se expandem e a arrecadação declina em períodos recessivos, levando a uma maior fragilidade fiscal. A política fiscal é considerada pró-cíclica quando o governo expande gastos em proporção maior que suas receitas durante as expansões, seja por motivações políticas ou fruto de restrições no mercado de crédito (Gavin; Perotti, 1997; Talvi; Vegh, 2005). 
Compreender a efetividade da política fiscal e seu comportamento cíclico é de fundamental importância. A escolha do nível de endividamento ótimo durante as recessões, a velocidade de ajuste das contas públicas quando a economia dá sinais de retomada e a necessidade de uso de regras fiscais depende de um diagnóstico correto do impacto de intervenções fiscais sobre a economia. Este trabalho pretende contribuir para essa discussão ao analisar o comportamento cíclico da fragilidade das finanças públicas no Brasil entre 1996 e 2019. O objetivo é utilizar o modelo de fator dinâmico para construir um índice de fragilidade fiscal que permita analisar o comportamento cíclico da política fiscal no Brasil por meio de modelos de vetores autorregressivos (VAR). A análise empírica verifica se as finanças públicas se deterioram durante expansões na atividade econômica, como ocorre em outros países emergentes.

As dificuldades em se garantir a estabilidade fiscal no Brasil têm despertado o interesse de pesquisadores em compreender os determinantes da fragilidade das finanças públicas e o seu impacto sobre a atividade econômica (Mendonça et al., 2009; Cavalcanti; Silva, 2010; Gadelha; Divino, 2013; Gobetti; Orair, 2015). No entanto, não foram identificados estudos que utilizassem modelos econométricos formais para, simultaneamente, derivar um índice de fragilidade do setor público e verificar sua relação com os agregados macroeconômicos.

Ferrari-Filho et al. (2010), Terra e Ferrari-Filho (2011; 2017) e Moura e Tiryaki (2016) desenvolveram trabalhos que se assemelham à iniciativa proposta no presente artigo. Ferrari-Filho et al. (2010) e Terra e Ferrari-Filho (2011; 2017) calcularam um índice de fragilidade financeira do setor público a partir de valores contemporâneos de variáveis de fluxo das finanças públicas. Esses autores analisaram o comportamento das finanças públicas com base na taxonomia apresentada por Minsky (1986) e não utilizaram análise econométrica para derivar o indicador de fragilidade fiscal ou para analisar seu comportamento cíclico.

Já Moura e Tiryaki (2016) adotaram a análise multivariada de fatores para derivar o índice de fragilidade das finanças públicas. Essa estratégia não é ideal, pois ignora o caráter não estacionário das séries temporais envolvidas na análise. Ademais, esses autores restringiram-se à análise da causalidade de Granger para verificar a relação entre o indicador de fragilidade fiscal e os agregados macroeconômicos.

O presente trabalho contribui para a análise do comportamento cíclico das finanças públicas no Brasil em dois aspectos. Primeiro, utiliza o método 
de fator dinâmico para construir o indicador de fragilidade fiscal incorporando um conjunto amplo de variáveis relacionadas às finanças públicas. Diversamente da estratégia adotada por Moura e Tiryaki (2016), o método do fator dinâmico leva em consideração a não estacionariedade das séries temporais utilizadas. $\bigcirc$ trabalho também contribui para a literatura com a estimação de modelos VAR que verificam a relação entre a fragilidade das finanças públicas e as flutuações de curto prazo na atividade econômica.

Os resultados das estimações indicam que choques positivos exógenos na produção aparentam reduzir a fragilidade das contas públicas no Brasil. Ademais, fatores que contribuem para promover a instabilidade macroeconômica também deterioram as finanças públicas, como choques adversos na volatilidade cambial.

Além desta introdução, o presente trabalho conta com mais cinco seções. Na segunda seção, são apresentados os referenciais teórico e empírico sobre o comportamento cíclico da política fiscal. A terceira seção detalha as variáveis utilizadas no estudo empírico. A quarta seção apresenta a metodologia econométrica dos modelos VAR, e a quinta seção analisa os resultados das estimações. Na última seção são apresentadas as conclusões.

\section{Política fiscal e ciclos econômicos: debate teórico e evidência empírica}

Na visão Keynesiana tradicional, a relação entre intervenções fiscais e o desempenho macroeconômico é estabelecida através do efeito multiplicador. Elevações nos gastos públicos e redução da tributação estimulam a demanda agregada, particularmente se o consumo é sensível a variações na renda corrente disponível. Com as taxas de juros mantidas constantes, conjectura-se que o multiplicador teria um sinal positivo e sua magnitude dependeria apenas da propensão marginal a consumir, sendo que o multiplicador associado a expansões nos gastos seria maior do que o multiplicador tributário (Hemming et al., 2002; Ramey, 2011).

Se a expansão dos gastos elevar o endividamento público, as taxas de juros podem crescer e apreciar o câmbio, reduzindo a magnitude do multiplicador fiscal. Esse efeito crowding out requer que o investimento e o consumo de bens duráveis respondam de maneira mais significativa às flutuações nas taxas de juros do que às variações na renda. Requer também 
que a elasticidade da demanda por moeda em relação à taxa de juros seja mais significativa do que a elasticidade renda e que o saldo de transações correntes seja sensível às flutuações na taxa de câmbio.

Os modelos que incorporam expectativas racionais introduzem aspectos dinâmicos à análise de impacto das intervenções fiscais (Aiyagari et al., 1992). Elevações nos gastos públicos financiados com endividamento aumentam a oferta de trabalho e a poupança no presente, pois os consumidores esperam maior ônus tributário no futuro (Equivalência Ricardiana). Ou seja, se os consumidores são forward-looking, a política fiscal pode se tornar inócua. Por outro lado, se o aumento nos gastos é financiado com tributos que geram distorções (e.g. impostos sobre a renda), a oferta de trabalho pode declinar e, nesse caso, o multiplicador será negativo.

O desequilíbrio fiscal financiado com endividamento crescente pode elevar o prêmio de risco das taxas de juros, reforçando o efeito crowding out (Alesina, 2012). Esses efeitos negativos são minimizados quando: a) as previsões são imperfeitas; b) os agentes preocupam-se somente com o curto prazo e apresentam comportamento não altruístico em relação às gerações futuras; e c) existem restrições de liquidez e imperfeições no mercado de capitais (Mankiw; Summers, 1984).

Em Modelos Novos-Keynesianos, que incorporam rigidez de preços em um arcabouço metodológico neoclássico, o potencial de impacto do multiplicador fiscal é reduzido (Smets; Wouters, 2007; Cogan et al., 2010). A magnitude do multiplicador somente se torna mais significativa em situações deflacionárias associadas à armadilha da liquidez (Eggertsson, 2011; Christiano et al., 2011). Em uma recessão severa, elevações nos gastos públicos sem aumentos na tributação geram expectativas de elevação na inflação. Com taxas nominais de juros próximas a zero, o aumento da inflação esperada reduz a taxa real de juros, estimulando a economia.

Multiplicadores fiscais mais significativos também são encontrados em modelos Novos-Keynesianos, que assumem um comportamento do tipo rule of thumb por parte dos consumidores ou uma elevada elasticidade para a curva oferta de trabalho (Gali et al., 2007). Comportamento do tipo rule of thumb ocorre quando o consumo é sensível a variações na renda corrente, em razão de restrições no acesso ao mercado de capitais, miopia ou dificuldade em perceber a importância da substituição intertemporal do consumo. Já quando a curva de oferta de trabalho é elástica, o efeito renda de elevações nos gastos públicos é significativo, pois o nível de emprego 
é completamente determinado por flutuações na demanda por trabalho.

Outros fatores também podem afetar o multiplicador fiscal, como problemas na defasagem de impacto de política fiscal, a presença de fricções financeiras e o viés deficitário por razões políticas. Mudanças significativas na esfera fiscal requerem aprovação do Legislativo, o que pode atrasar a execução de novas políticas, tornando a política fiscal ineficaz como mecanismo estabilizador dos ciclos econômicos.

Imperfeições no mercado de crédito, por sua vez, podem gerar um comportamento pró-cíclico da política fiscal, com aumento dos gastos públicos em proporção maior do que a arrecadação tributária durante expansões na atividade econômica. Gavin e Perotti (1997) e Kaminski et al. (2004), por exemplo, acreditam que a contração na oferta de crédito durante as recessões inviabiliza a expansão nos gastos públicos necessária para estabilizar os ciclos econômicos. Nas expansões, quando o acesso ao crédito se torna mais facilitado, os governos aproveitam o menor racionamento de crédito e elevam os gastos públicos. Esse efeito seria particularmente evidente em economias emergentes.

O viés deficitário por motivações políticas pode ser fruto da ausência de preocupação com gerações futuras por parte de eleitores, de pressões do público para que as rendas políticas sejam limitadas e da influência de coalizões políticas. Alesina e Tabellini (2005) argumentam que os eleitores exigem maior oferta de bens públicos quando a economia expande para impedir que os governos se apropriem de rendas, particularmente quando a corrupção é difusa. Frankel et al. (2013) e Bashar et al. (2017) mostram que países com governança institucional menos robusta tendem a apresentar políticas fiscais pró-cíclicas.

O "efeito voracidade" seria outro motivo político para se observarem políticas fiscais pró-cíclicas (Tornell; Lane, 1999; Talvi; Vegh, 2005). Durante expansões, quando os recursos disponíveis são mais abundantes, a disputa pelos recursos comuns entre os grupos políticos que compõem o governo é mais severa, gerando déficits fiscais.

\subsection{Evidência empírica}

A evidência empírica mostra que expansões fiscais ocorrem em períodos recessivos, sendo que países desenvolvidos exibem, normalmente, multiplicadores fiscais mais significativos do que países emergentes. A magni- 
tude do multiplicador também depende da situação fiscal do país anteriormente ao processo recessivo: países com déficits fiscais ou endividamento significativo antes da contração econômica apresentam políticas fiscais menos efetivas e crowding out de maior magnitude.

Estudos utilizando dados de séries temporais indicam que a magnitude do multiplicador fiscal se situa entre 0,6 e 1,8 (Ramey, 2011). Já Auerbach e Gorodnichenko (2012) encontram resultados diferentes a depender do estado da economia: o multiplicador situa-se entre 0,0 e 0,5 durante as expansões e entre 1,0 e 1,5 nas recessões. Um multiplicador fiscal inferior à unidade significa que os outros componentes do produto interno bruto (PIB) declinam com a expansão nos gastos do governo.

Estudos utilizando dados em cross-section de regiões em um mesmo país permitem verificar a importância da heterogeneidade nos impactos de iniciativas fiscais. Esses estudos costumam encontrar multiplicadores entre 1,5 e 1,8, com os valores mais elevados ocorrendo em períodos recessivos (Ramey, 2011). Já estudos em cross-section com dados internacionais costumam evidenciar declínio nos gastos e menores déficits fiscais durante expansões na produção, particularmente na presença de elevado endividamento e expressivo prêmio de risco nas taxas de juros (Hemming et al., 2002; Nickel; Tudyka, 2014).

A existência de política fiscal pró-cíclica é comum em países emergentes, particularmente naqueles com fraca governança institucional (Alesina; Tabelini, 2005; Frenkel et al., 2013). Os estudos mostram que a associação positiva entre corrupção e política pró-cíclica ocorre majoritariamente em democracias, um indicativo de que eleitores exigem uma maior oferta de bens públicos durante expansões.

A importância de restrições de crédito também pode explicar a existência de política fiscal pró-cíclica em países emergentes. Gavin e Perotti (1997), Caballero e Krishnamurthy (2004) e Frenkel et al. (2013) mostram que países com acesso limitado aos mercados de capital internacionais e com mercados financeiros domésticos menos desenvolvidos costumam apresentar políticas fiscais pró-cíclicas.

O desempenho das finanças públicas no Brasil tem sido extensivamente analisado, mas com objetivos ou metodologias diversos do presente trabalho. Mendonça et al. (2009), por exemplo, estimam uma função de reação fiscal e mostram que o superávit fiscal responde positivamente à produção, evidenciando um comportamento contracíclico da política fiscal, resultado 
ratificado por Pires (2014). Gadelha e Divino (2013), por outro lado, encontram um viés pró-cíclico da política fiscal.

Já Cavalcanti e Silva (2010) empregam um modelo VAR para avaliar o impacto da política fiscal sobre a atividade econômica, levando em consideração o papel da dívida pública. Os autores argumentam que estudos que não analisam conjuntamente variações no orçamento e no endividamento público tendem a amplificar o impacto da política fiscal sobre a produção.

Schettini (2014) mostra como a política monetária afeta os superávits primários do governo, enquanto outros trabalhos buscam analisar explicações alternativas para o desempenho das finanças públicas, tais como as políticas de desoneração tributária entre 2005 e 2014 e a rigidez das despesas governamentais no período pós-Plano Real (Orair, 2015; Gobetti; Orair, 2015; 2017; Oliveira et al., 2017).

Como apontado anteriormente, poucos são os estudos que derivam um índice de fragilidade fiscal e, quando o fazem, não utilizam modelos econométricos formais. Ferrari-Filho et al. (2010) e Terra e Ferrari-Filho (2011; 2017) construíram um índice de fragilidade fiscal para o Brasil com base na taxonomia desenvolvida por Minsky (1986) e avaliaram seu desempenho temporal, mas sem utilizar modelos econométricos para estabelecer a conexão entre fragilidade fiscal e ciclos econômicos.

\section{Descrição dos dados e das variáveis}

O trabalho utiliza dados mensais de contas públicas do governo central e indicadores macroeconômicos entre julho de 1996 e fevereiro de 2019 (BACEN, 2019; IBGE, 2019). Nesse período, é possível identificar três fases distintas no comportamento das finanças públicas (Figura 1). ${ }^{2}$ No final dos anos de 1990, o país enfrentou grande instabilidade econômica com as crises asiática e russa e com o abandono da política de bandas cambiais. Nessa primeira fase, observou-se uma leve deterioração do resultado primário e crescente endividamento público.

A segunda fase compreendeu o período entre 1999 e 2010 e foi marcada pela adoção do regime de metas de inflação, metas de superávit primário e

2 Para uma discussão detalhada das definições associadas às estatísticas fiscais e da evolução da política fiscal no Brasil, ver Gobetti e Orair (2015; 2017), Oliveira et al. (2017) e Oreiro (2017), entre outros. 
aprovação da Lei de Responsabilidade Fiscal (Mendonça et al., 2009; Schettini, 2014). Essas iniciativas promoveram maior estabilidade econômica e um desempenho fiscal mais favorável, que foi abalado apenas pela crise de 2008.

Figura 1 Desempenho fiscal do governo federal: 1996-2019

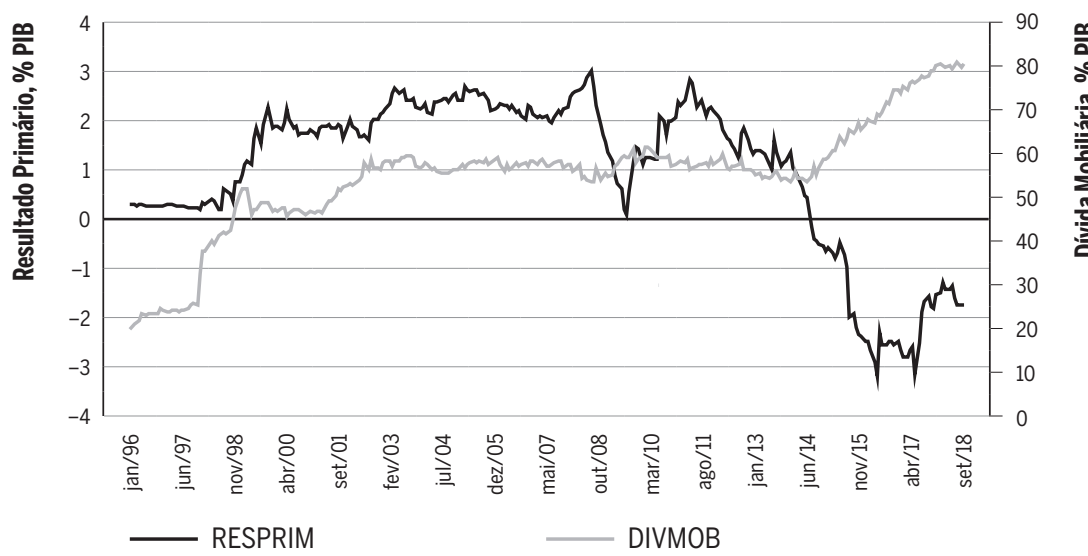

Fonte: BACEN (2019).

Nota: Valores acumulados nos últimos 12 meses.

Figura 2 Evolução das receitas e despesas do governo federal

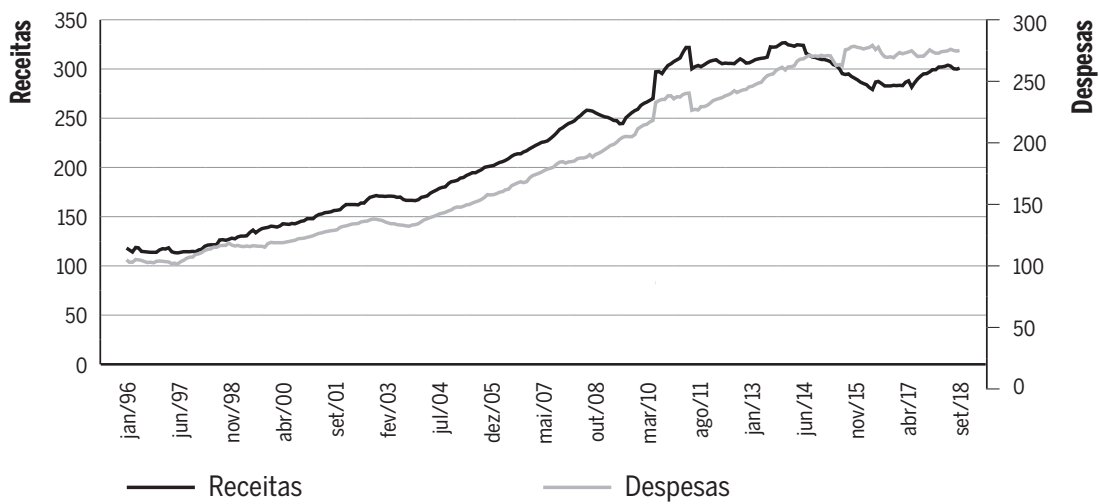

Fonte: $\operatorname{BACEN}$ (2019).

Nota: Valores em bilhões de reais ajustados pelo IPCA (base: Jan/1995) e acumulados nos últimos 12 meses.

A terceira fase iniciou-se no segundo semestre de 2011, quando o resultado primário começou a apresentar uma crescente deterioração. Esse de- 
sempenho deveu-se ao contínuo crescimento das despesas públicas e às diversas iniciativas de desoneração fiscais adotadas (Orair, 2015; Gobetti; Orair, 2015). Até o final de 2014, o crescimento das receitas não acompanhou a significativa expansão nos gastos públicos e, a partir do último trimestre daquele ano, as receitas passaram a apresentar uma tendência declinante em razão do desaquecimento econômico (Figura 2). A resultante contração do resultado primário se acentuou, elevando o endividamento público de maneira significativa, principalmente a partir do segundo semestre de 2015.

Compreender como uma conjuntura fiscal desfavorável se relaciona com desempenho macroeconômico é a motivação deste trabalho. Nesta seção, são inicialmente definidos os indicadores de volatilidade macroeconômica. Posteriormente, são detalhadas as variáveis utilizadas na construção do índice de fragilidade fiscal, seguindo-se com a descrição da metodologia de fator dinâmico e a derivação do indicador de fragilidade fiscal. Por fim, são apresentadas as variáveis de controle utilizadas nos modelos VAR.

\subsection{Medidas de volatilidade dos ciclos econômicos}

Foram utilizadas três variáveis alternativas como indicadores de desempenho macroeconômico: PIB, Índice de Atividade Econômica do Banco Central (IBC-BR) e índice de produção industrial. Inicialmente, utilizou-se o filtro de Hodrick-Prescott (HP) para derivar os componentes cíclicos dessas variáveis. Esse filtro evita a exclusão de observações, mas produz frequentemente relações dinâmicas espúrias e apresenta viés de final da amostra (Hamilton, 2017; Schuler, 2018).

Filtros alternativos com maior precisão, como os filtros do tipo bandpass desenvolvidos por Baxter e King (1999) e por Christiano e Fitzgerald (2003), levam a uma perda significativa de observações. Como alternativa ao filtro HP, utilizou-se o filtro proposto por Hamilton (2017), que produz melhores estimativas no final da amostra do que o filtro HP, embora apresente a desvantagem de enfatizar as flutuações com duração mais longa que um ciclo econômico típico e de ignorar flutuações com duração inferior a dois anos (Schuler, 2018). O uso de filtros alternativos e de variáveis macroeconômicas diversas permite verificar a robustez dos resultados.

Em relação ao PIB, utilizou-se a série mensal acumulada nos últimos 12 
meses, deflacionando-a pelo índice nacional de preços ao consumidor amplo (IPCA). A escolha pelo IPCA foi feita em virtude da indisponibilidade de dados mensais para o deflator do PIB. Após obter os valores reais do PIB e calcular o logaritmo natural da série, as flutuações de baixa frequência foram removidas. O componente cíclico obtido com o filtro HP foi nomeado CYCPIB, enquanto que o componente obtido com o filtro de Hamilton foi nomeado HAMPIB.

O componente cíclico do IBC-BR foi obtido apenas com o filtro HP e nomeado $C Y C I B C$. O número mais restrito de observações disponíveis para essa série temporal inviabilizou o uso do filtro de Hamilton (janeiro de 2003 e fevereiro de 2019). Alternativamente ao PIB e ao IBC-BR, utilizou-se também o índice de produção industrial acumulada nos últimos 12 meses. Nesse caso, nomeou-se o componente cíclico como CYCIND ou HAMIND, a depender do filtro utilizado.

\subsection{Indicador de fragilidade das finanças públicas}

A construção do indicador de fragilidade fiscal fundamenta-se na hipótese de que fatores latentes não observáveis determinam o comportamento das variáveis que evidenciam a saúde financeira do governo. A utilização de um conjunto amplo de séries temporais reduz possíveis vieses com informações restritas e tem sido recomendada em trabalhos empíricos em macroeconomia. Modelos de fatores dinâmicos possibilitam incorporar as informações disponíveis e, ao mesmo tempo, evitar erros de medidas e variação idiossincrática em séries individuais (Stock; Watson, 2016).

As nove variáveis escolhidas para compor o índice de fragilidade do setor público são comumente utilizadas na literatura (Cavalcanti; Silva, 2010; Athayde; Vianna, 2015; Moura; Tiryaki, 2016; Oliveira et al., 2017). Os principais critérios na seleção das variáveis foi seu conteúdo informativo e a disponibilidade de séries temporais longas que garantem maior robustez para a análise econométrica. Optou-se por não utilizar as estatísticas de estados e municípios em razão de dificuldades com a cobertura e intempestividade desses dados regionais (Gobetti; Orair, 2015). ${ }^{3}$

3 Outra dificuldade encontrada na coleta de dados de contas públicas refere-se a mudanças de metodologia na divulgação das séries temporais. Nessas situações, adotou-se a técnica de data splicing por extrapolação reversa da série mais atualizada para obter dados compatíveis 
O resultado primário do tesouro nacional representa uma medida de robustez das finanças públicas (RESPRIM). Trata-se da diferença entre as receitas e as despesas fiscais não financeiras. As receitas fiscais compreendem as receitas administradas e não administradas pela Receita Federal, incentivos fiscais e a arrecadação líquida da previdência social. Já as despesas primárias incluem majoritariamente os benefícios previdenciários e despesas com pessoal e encargos. Foram utilizados dados acumulados nos últimos 12 meses em razão do PIB.

Gobetti e Almeida (2016) argumentam que a maior dificuldade em se trabalhar com dados do orçamento primário relaciona-se às distorções causadas pela forma como é feito o registro de receitas e despesas, em particular o uso de artifícios contábeis para subestimar despesas públicas. Por isso, evitou-se trabalhar com os itens desagregados de receitas e despesas. A derivação do índice de fragilidade fiscal permite lidar de maneira mais efetiva com essa contabilidade criativa, pois o fator latente reflete a tendência comum das variáveis identificadas, minimizando possíveis vieses causados por erros de medida em variáveis específicas.

O orçamento primário não incorpora as receitas e despesas financeiras do tesouro nacional. Por essa razão, incluiu-se na composição do índice variáveis associadas à necessidade de financiamento do setor público (NFSP) do governo federal e banco central, mensuradas em saldos acumulados nos últimos 12 meses em razão do PIB:

- NFSP representa a necessidade de financiamento interno (resultado nominal); e

- NFSPJUR contabiliza os juros nominais incidentes sobre a dívida interna.

Também foram selecionadas variáveis relacionadas ao endividamento do setor público. A dívida pública federal pode ser segmentada em dívida pública mobiliária interna e externa. A dívida interna é composta pelos títulos públicos emitidos pelo tesouro e que são registrados na Câmara de Custódia e Liquidação (CETIP) ou no Sistema Especial de Liquidação e da Custódia (SELIC). Para a composição do índice de fragilidade fiscal, foram utilizados o saldo da dívida mobiliária interna total emitida em razão do PIB $(D I V M O B)$ e duas variáveis relacionadas à estrutura de vencimento da dívida: 
- PRAZO indica o tempo médio que resta para o vencimento dos títulos que compõem o estoque da dívida;

- VIDA representa o tempo médio do prazo de vencimento desses títulos.

Infere-se que reduções no tempo médio para o vencimento e no tempo médio do prazo de vencimento dos títulos emitidos levam a uma maior a fragilidade das finanças públicas.

Por fim, outras três variáveis relacionadas à composição da dívida mobiliária do setor público também foram selecionadas: LTN, LTNDUR e LFT. A variável $L T N$ representa a razão entre o saldo em custódia das letras do tesouro nacional e o saldo total de títulos domésticos emitidos. Como as LTNs são títulos prefixados, envolvem menor risco que títulos atrelados à Selic ou indexados à inflação. LTNDUR, por sua vez, indica o tempo médio do prazo de vencimento das LTNs emitidas. Por fim, LFT representa a razão entre o saldo em custódia das letras financeiras do tesouro nacional e o saldo total de títulos domésticos emitidos. As LTFs são títulos que envolvem maior exposição ao risco do que as LTNs, pois são indexadas à taxa Selic, que é sujeita às intervenções de política monetária e à volatilidade do mercado.

\subsubsection{Modelo de fator dinâmico}

A análise de fatores multivariada não pode ser utilizada se os fatores seguem um processo que se modifica ao longo do tempo. Ou seja, na presença de componentes autorregressivos, sugere-se o uso do modelo de fator dinâmico (Geweke, 1977; Stock; Watson, 2016). Esse método busca extrair um número reduzido de indicadores que não podem ser mensurados diretamente, mas que determinam o comportamento conjunto de variáveis relacionadas. No presente estudo, trabalha-se com a hipótese de que o comportamento das variáveis fiscais reflete as motivações dos gestores públicos e possíveis restrições na execução da política fiscal, sejam de caráter legal, institucional ou financeiro.

A premissa do modelo é que o movimento sincronizado de um vetor de séries temporais com elevada dimensão $\left(X_{i t}\right)$ é gerado por um conjunto de poucos fatores latentes $\left(f_{t}\right)$ e um vetor de erros idiossincráticos com média zero $\left(e_{t}\right)$. Presume-se que o vetor de fatores latentes segue um processo 
de séries temporais, normalmente descrito por um vetor autorregressivo. Stock e Watson (2016) definem:

$$
\begin{aligned}
& X_{i t}=\lambda_{i}(L) f_{t}+e_{t} \\
& f_{t}=\psi(L) f_{t-1}+\eta_{t}
\end{aligned}
$$

Existe um número $N$ de variáveis $X_{i}$ incluídas na análise, de forma que $X_{i t}$ e $e_{t}$ possuem dimensão $N \times 1$ e t representa a unidade temporal. Define-se $q$ como o número de fatores dinâmicos que compõe a matriz $f$, sendo que $f_{t}$ e $\eta_{t}$ possuem dimensão $q \times 1$. Tipicamente, $q$ terá uma dimensão bem inferior a $N$.

As matrizes polinomiais defasadas $\lambda(L)$ e $\psi(L)$ possuem dimensões $N \times q$ e $q \times q$, respectivamente, com $L$ representando o operador de defasagem. O polinomial defasado $\lambda_{i}(L)$ é chamado de carga do fator dinâmico da variável $X_{i t}$, de forma que $\lambda_{i}(L) f_{t}$ é a fração de $X_{i t}$ que é explicada pelos componentes comuns. Os termos de erro $e_{t}$ e $\eta_{t}$ não são correlacionados. Os parâmetros das equações são estimados utilizando máxima verossimilhança, e o filtro de Kalman é aplicado para obter estimativas eficientes dos fatores.

Existem diversas estratégias metodológicas para a derivação de fatores latentes e o seu uso em macroeconomia aplicada tem sido comum (Stock; Watson, 2016). É possível lidar com sistemas de elevada dimensão associados à análise VAR (factor augmented vector autoregression models) ou com sistemas de menor dimensão (small state-space dinamic fator model). Como o presente trabalho busca derivar um único indicador de fragilidade de política fiscal, optou-se por utilizar um sistema de menor dimensão, assim como Quah e Sargent (1993) e Aruoba et al. (2009).

Testes de raiz unitária indicaram a necessidade do uso de primeiras diferenças das variáveis originais para torná-las estacionárias, um procedimento necessário para a estimação do modelo de fator dinâmico. ${ }^{4} \mathrm{~A}$ Tabela 1 apresenta os resultados da estimação do modelo, pressupondo-se que o fator latente segue um processo autorregressivo de segunda ordem.

As estimativas indicam que elevações no fator refletem maior fragilidade financeira. A necessidade de financiamento do setor público (NFSP e mentos econométricos. Os resultados não apresentados no texto podem ser obtidos mediante solicitação aos autores. 
NFSPJUR), o saldo da dívida mobiliária em relação ao PIB e a participação das LFTs na composição da dívida pública são positivamente relacionados com o fator. Por outro lado, resultados primários mais favoráveis, crescentes participações das LTNs na composição da dívida e prazos mais alongados na emissão de títulos são associados com menores valores para o fator.

Os resultados revelam baixa persistência do indicador, pois somente sua primeira defasagem é estatisticamente relevante. Salienta-se, ainda, que o fator é um preditor significativo para quatro das variáveis selecionadas como medidas de saúde das finanças públicas: NFSP, NFSPJUR, RESPRIM e VIDA.

Tabela 1 Modelo de fator dinâmico

\begin{tabular}{lrrrr}
\hline Fator & Coeficiente & Erro padrão & $\mathbf{z}$ & $\mathbf{P}>|\mathbf{z}|$ \\
\hline L1. & $0,102^{*}$ & 0,060 & 1,690 & 0,091 \\
\hline L2. & 0,075 & 0,060 & 1,240 & 0,214 \\
\hline D.NFSP & $0,329^{* * *}$ & 0,014 & 23,320 & 0,000 \\
\hline D.NFSPJUR & $0,189^{* * *}$ & 0,013 & 14,970 & 0,000 \\
\hline D.RESPRIM & $-0,130^{* * *}$ & 0,011 & $-11,610$ & 0,000 \\
\hline D.DIVMOB & 0,097 & 0,075 & 1,290 & 0,198 \\
\hline D.LTNDUR & $-0,071$ & 0,059 & $-1,190$ & 0,233 \\
\hline D.LTN & $-0,027$ & 0,105 & $-0,260$ & 0,798 \\
\hline D.LFT & 0,035 & 0,158 & 0,220 & 0,823 \\
\hline D.VIDA & $-0,097^{* *}$ & 0,043 & $-2,220$ & 0,026 \\
\hline D.PRAZO & $-0,041$ & 0,055 & $-0,750$ & 0,452 \\
\hline No observações & 272 & & & \\
\hline Wald $\chi^{2}(11)$ & 549,04 & Prob $>\chi^{2}$ & 0,000 & \\
\hline
\end{tabular}

Fonte: Elaboração própria.

Nota: O prefixo D indica que a variável foi incluída na estimativa em primeiras diferenças; ${ }^{*},{ }^{*} e^{* * *}$ indicam significância estatística de 10\%, 5\% e 1\%, respectivamente.

Na Figura 3, é possível observar o comportamento do fator estimado durante o período em análise. Períodos recessivos são indicados pelas regiões sombreadas, conforme a datação dos ciclos econômicos realizada pelo CODACE (2017). O indicador exibe elevada variância em razão de as variáveis originais estarem em primeiras diferenças.

Considerando que valor do índice não possui interpretação direta, o que se pode inferir da análise da Figura 3 é que a fragilidade fiscal tende a 
se elevar nos períodos recessivos, aparentemente indicando um comportamento contracíclico da política fiscal no Brasil. Verifica-se, também, que o indicador de fragilidade fiscal se eleva em outros momentos no período analisado, embora em menor magnitude do que durante períodos recessivos. A análise VAR descrita na próxima seção permitirá verificar com maior precisão o comportamento cíclico do indicador de fragilidade fiscal.

\section{Figura 3 Indicador de fragilidade das finanças públicas}

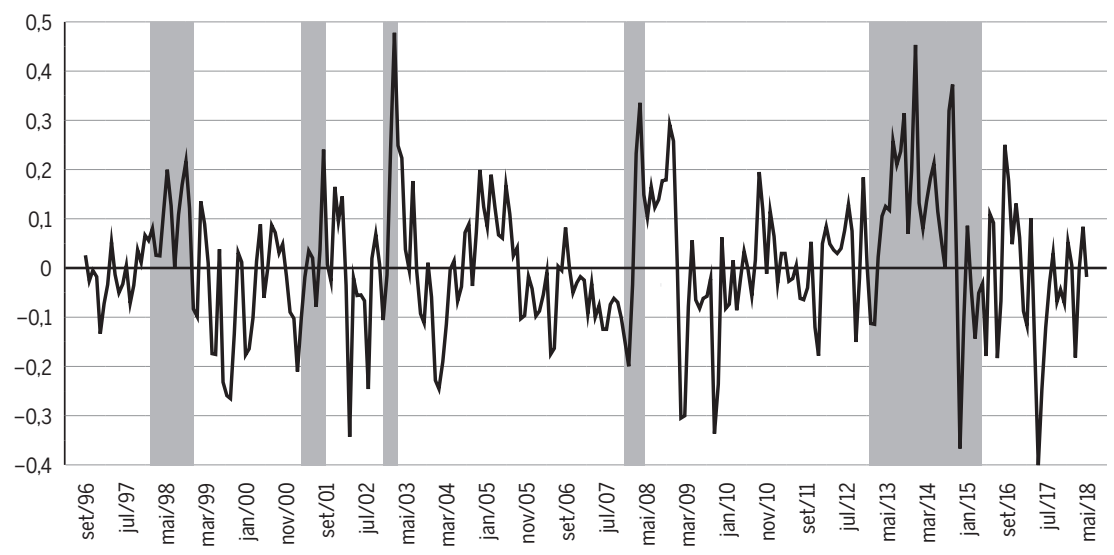

Fonte: Elaboração própria.

Nota: Intervalos em azul indicam períodos recessivos (CODACE, 2017).

\subsection{Variáveis de controle}

A inclusão de variáveis de controle é importante para evitar vieses associados à omissão de variáveis relevantes. Foram selecionados indicadores comumente identificados pela literatura como determinantes da volatilidade dos ciclos econômicos (Backus et al., 1992; Karras; Song, 1996; Ferreira da Silva, 2002):

- O logaritmo do índice de preços obtido a partir das taxas anualizadas de crescimento do IPCA (IPCA) constitui um indicador das incertezas e distorções causadas por elevadas taxas de inflação (base: janeiro de 1995). A estabilidade da inflação sinaliza que a política monetária está sendo efetiva.

- O componente cíclico do resíduo de Solow (SOLOW) captura o im- 
pacto de choques exógenos de produtividade na economia, que são considerados como principal determinante dos ciclos econômicos pela teoria dos ciclos reais de negócios (Hodrick; Prescott, 1997).

- Como medida da instabilidade cambial, utilizou-se o desvio padrão da taxa nominal de câmbio nos últimos 12 meses, expressa em US\$/ $\mathrm{R}$ \$ (CAMBIO). Taxas de câmbio estáveis facilitam o planejamento dos agentes econômicos e reduzem a volatilidade dos ciclos econômicos.

- O grau de vulnerabilidade da carteira de crédito é um indicador da fragilidade do sistema financeiro. A percepção de maior exposição ao risco de não pagamento tende a gerar racionamento de crédito, reduzindo o ritmo da atividade econômica. $\bigcirc$ grau de vulnerabilidade foi medido pela razão entre a provisão para perdas prováveis com créditos e o total do crédito concedido pelas instituições financeiras (PROV).

Extraiu-se o componente cíclico de todas as variáveis de controle. Os prefixos CYC e HAM associados ao nome da série indicam o uso do filtro HP e do filtro de Hamilton, respectivamente.

\section{Metodologia econométrica}

O modelo VAR é constituído por um sistema de equações em que cada variável é função dos seus valores defasados, dos valores atuais e defasados das demais variáveis que compõem o sistema e do termo de erro (Lutkepohl, 2005; Pesaran; Shin, 1998). Genericamente, o modelo pode ser representado pela expressão:

$$
x_{t}=\sum_{i=1}^{p} \Phi_{i} x_{t-i}+\Psi w_{t}+\varepsilon_{t}, \quad t=1,2, \ldots, T,
$$

onde $x_{t}=\left(x_{1 t}, x_{2 t}, \ldots, x_{m t}\right)^{\prime}$ é um vetor $m \times 1$ de variáveis dependentes determinadas conjuntamente; $p$ é o número de defasagens; $w_{t}$ é um vetor $q \times 1$ de variáveis exógenas e/ou determinísticas; e $\Phi_{i}$ (vetor $\left.m \times m\right)$ e $\Psi(m \times q)$ são matrizes de coeficientes.

O modelo VAR somente é estável se as variáveis são estacionárias. Essa condição é atendida no presente trabalho, pois os procedimentos de extra-

5 O resíduo foi obtido pela diferença entre a variação no logaritmo da produção em dois períodos consecutivos e o produto de $(1-\alpha)$ pela variação no logaritmo do emprego (Karras; Song, 1996). Este trabalho definiu $\alpha=0,4$ (Ellery, 2014). 
ção do componente de baixa frequência com o uso dos filtros e a estimação do modelo de fator dinâmico geram séries estacionárias.

A escolha pelo modelo VAR teve três motivações. Primeiramente, o modelo VAR permite analisar as relações de curto prazo entre as variáveis, diferentemente do modelo de vetor de correção de erros, que pressupõe a existência de uma relação de equilíbrio de longo prazo. A segunda motivação deu-se em razão de o modelo VAR incorporar diretamente o caráter endógeno das séries temporais estudadas. Por fim, o uso do modelo VAR é indicado quando não é possível identificar a verdadeira forma estrutural e pretende-se, apenas, gerar previsões da trajetória futura das variáveis endógenas. ${ }^{6}$

Foram estimados cinco modelos VAR distintos: ${ }^{7}$

\title{
Moldelo 1
}

$$
\begin{aligned}
& x=[C Y C P I B \text { CYCIPCA CYCCAMBIO CYCSOLOW } \\
& \text { CYCPROV FATORPF }]
\end{aligned}
$$

\section{Moldelo 2}

\author{
$x=[C Y C I B C$ CYCIPCA CYCCAMBIO CYCSOLOW \\ CYCPROV FATORPF]
}

\section{Moldelo 3}

\author{
$x=[C Y C I N D$ CYCIPCA CYCCAMBIO CYCSOLOW \\ CYCPROV FATORPF]
}

\section{Moldelo 4}

$$
\begin{aligned}
& x=[H A M P I B \text { HAMIPCA HAMCAMBIO HAMSOLOW } \\
& \text { HAMPROV FATORPF }]
\end{aligned}
$$

\section{Moldelo 5}

$$
\begin{aligned}
& x=[H A M I N D \text { HAMIPCA HAMCAMBIO HAMSOLOW } \\
& \text { HAMPROV FATORPF }]
\end{aligned}
$$

6 Se o objetivo do trabalho fosse mostrar que a fragilidade fiscal causa as flutuações econômicas, então seria indicado estimar um modelo de VAR estrutural, com a definição de uma estratégia de identificação para choques exógenos na fragilidade fiscal.

7 Como apontado anteriormente, restrições no tamanho da amostra impossibilitaram o uso do filtro de Hamilton para obter o componente cíclico do IBC-BR. 


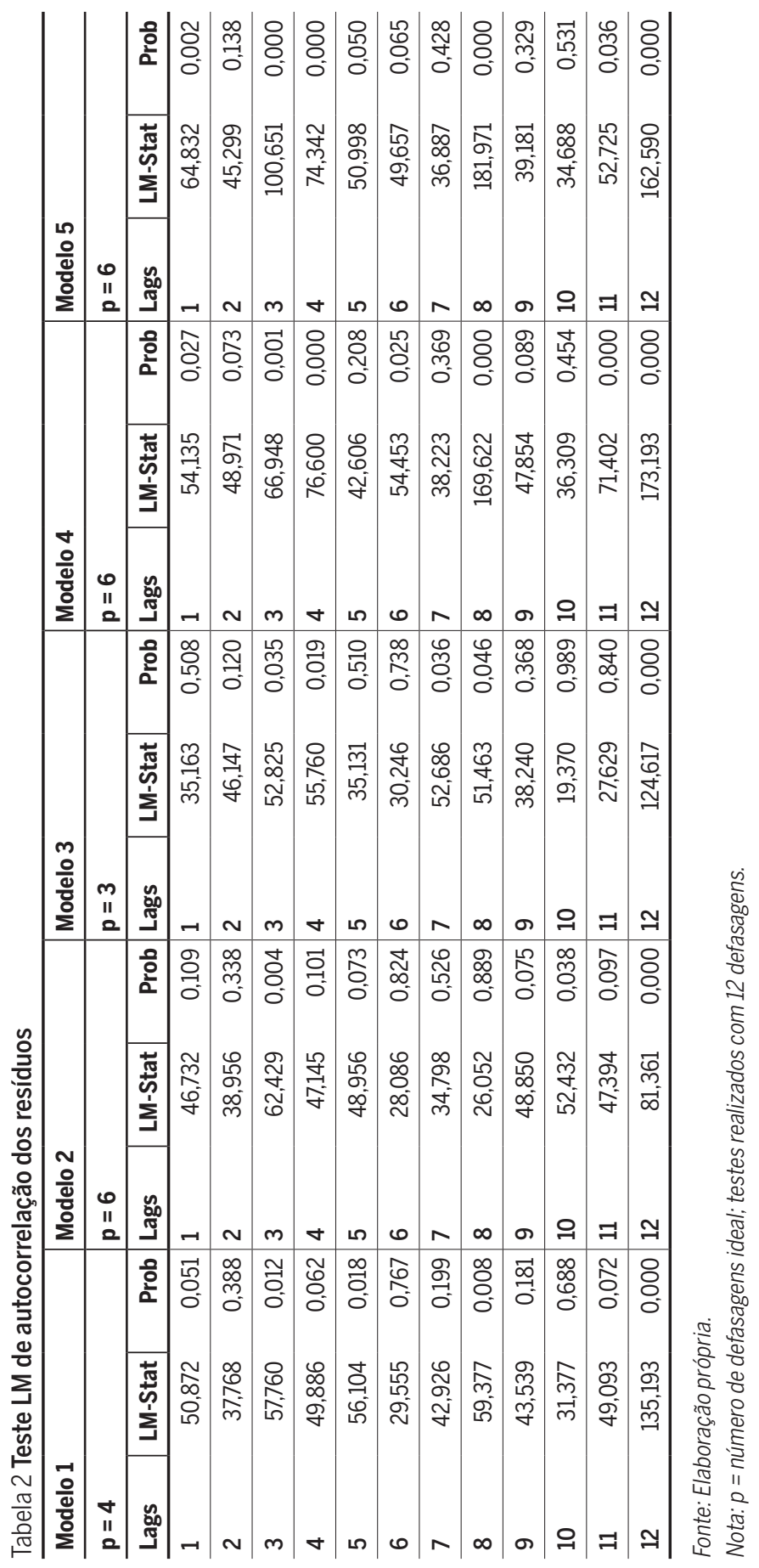


O VAR é fundamentado em três suposições, quais sejam: resíduos não correlacionados, estabilidade dinâmica e ausência de colinearidade perfeita entre as variáveis do sistema. Pesaran e Shin (1998) representam essas hipóteses com as seguintes condições:

a) $E\left(\varepsilon_{t}\right)=0, E\left(\varepsilon_{t} \varepsilon_{t}^{\prime}\right)=\sum$ para todo $t$, onde $\sum=\sigma_{i j}(i, j=1,2, \ldots m)$ é uma matriz $m \times m$ positiva definida, $E\left(\varepsilon_{t} \varepsilon_{t^{\prime}}^{\prime}\right)=0$ para todo $t=t^{\prime}$ e $E\left(\varepsilon_{t} \mid w_{t}\right)=0$;

b) Todas as raízes de $\left|I_{m}-\sum_{i=1}^{p} \Phi_{i} z^{i}\right|=0$ estão fora do círculo unitário; e

c) $x_{t-1}, x_{t-2}, \ldots, x_{t-p}, w_{t}, t=1,2, \ldots, T$ não são colineares perfeitos.

Para que essas condições sejam atendidas, é preciso definir o número mínimo de defasagens, $\mathrm{p}$, que garante a ausência de autocorrelação. Testes de seleção de ordem de defasagens baseados nos critérios de Erro Final de Previsão, Akaike, Schwarz e Hannan-Quinn indicaram o uso de duas ou 12 defasagens nos modelos 1, 4 e 5; duas ou três defasagens no modelo 2; e duas ou quatro defasagens no modelo 3.

Testes LM de autocorrelação dos resíduos foram utilizados para indicar o valor de p para cada modelo. Os resultados na Tabela 2 indicam ser suficiente o uso de quatro defasagens no Modelo 1; seis defasagens nos Modelos 2, 5 e 6; e três defasagens no Modelo 3. Essa conclusão é ratificada pelos os testes de estabilidade dinâmica ilustrados na Figura $4 .{ }^{8}$

A análise dos efeitos de choques em uma variável sobre as demais variáveis endógenas é realizada via estimação de funções de resposta a impulso e análise de decomposição da variância. As funções de resposta a impulso mostram o efeito desses choques em um determinado período de tempo sobre os valores futuros esperados das variáveis endógenas. Já análise de decomposição da variância contabiliza o percentual da variância de uma variável atribuível a cada variável endógena.

Os resultados das funções de resposta a impulso e de decomposição de variância são sensíveis ao ordenamento das variáveis. Duas condutas foram adotadas para verificar a robustez dos resultados. A primeira estra-

8 Embora os resíduos mostrem-se heterocedásticos, não apresentam distribuição normal. Para Lutkepohl (2005), ausência de normalidade pode indicar não linearidades ou mudanças estruturais, mas a análise pode ser conduzida utilizando o VAR, pois vários dos procedimentos estatísticos permanecem válidos. 
tégia utilizou testes de exogeneidade em bloco, que indica a ordem estatisticamente consistente das variáveis no modelo e permite estimar funções de resposta a impulso e decomposição de variância com base na decomposição de Cholesky (Lutkepohl, 2005). A variável mais exógena apresenta o menor valor da estatística qui-quadrado e deve ser a primeira listada no ordenamento do modelo VAR, seguida das variáveis com grau crescente de endogeneidade. A Tabela 3 apresenta os resultados dos testes de exogeneidade em bloco e indicam o ordenamento apropriado para cada modelo.

Figura 4 Raízes inversas do polinômio característico autorregressivo

\section{Modelo 1}

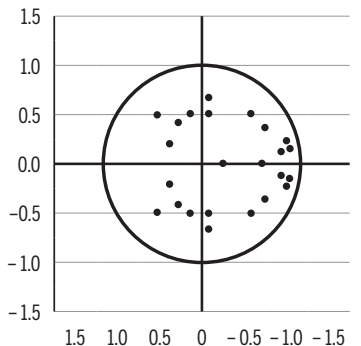

\section{Modelo 4}

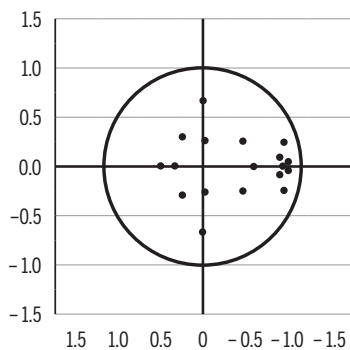

\section{Modelo 2}
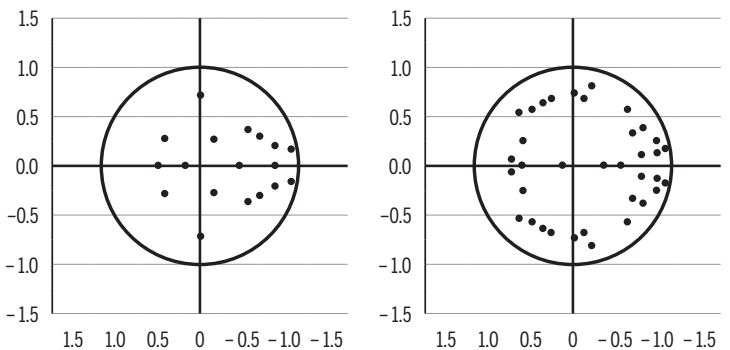

\section{Modelo 5}

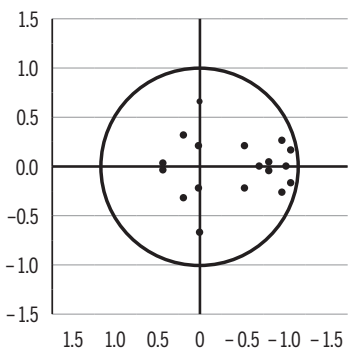

Fonte: Elaboração própria.

A segunda estratégia estimou funções de resposta a impulsos generalizados propostas por Pesaran e Shin (1998), que não são sensíveis ao ordenamento das variáveis. Para os referidos autores, os resultados obtidos com as funções de resposta a impulsos generalizados são únicos e consideram os padrões históricos de correlação que são observados entre os diversos choques. 


\section{Resultados}

Exceto para a análise de variância, todos os demais resultados apresentados nesta seção foram obtidos com base em estimativas utilizando impulsos generalizados. Os resultados das funções de resposta a impulso com base na decomposição de Cholesky são similares e não serão apresentados por limitação de espaço.

Inicialmente, procurou-se avaliar os impactos de choques exógenos no componente cíclico da produção e na fragilidade das finanças públicas (Figura 5). ${ }^{9}$ Choques positivos na produção produzem uma resposta estatisticamente significante na fragilidade fiscal apenas quando se utiliza o componente cíclico da produção industrial como medida de volatilidade macroeconômica. Elevações em CYCIND reduzem a fragilidade fiscal entre o terceiro e o quinto meses posteriores ao choque, apesar da fragilidade fiscal se mostrar ascendente entre o décimo e o décimo oitavo meses subsequentes ao choque. Choques em HAMIND, no entanto, reduzem a fragilidade fiscal de maneira mais representativa em magnitude e em duração, particularmente entre o terceiro e o oitavo meses posteriores ao choque.

Assim como em Mendonça et al. (2009) e Pires (2014), esses resultados indicam que a política fiscal no Brasil aparenta se comportar de maneira contracíclica, com maior equilíbrio no orçamento e menor necessidade de financiamento e endividamento em fases de expansão da atividade econômica. Ainda na Figura 5, observa-se que choques no indicador de fragilidade fiscal não afetam a volatilidade da produção, indicando que os desequilíbrios fiscais não contribuem isoladamente para a volatilidade dos ciclos econômicos. Essa interpretação é confirmada pelo fato de que as demais varáveis macroeconômicas inseridas no modelo VAR também não respondem de maneira estatisticamente significante a choques em FATOR.${ }^{10}$ Similarmente, Oreiro (2017) defende que a fragilidade fiscal observada mais recentemente no país aparenta ser reflexo da severa contração econômica, e não sua causa.

Para verificar a robustez dos resultados, ilustra-se o comportamento das demais variáveis endógenas em resposta a choques positivos no componente cíclico da produção na Figura 6. De maneira geral, os resultados mostram-se alinhados aos fatos estilizados sobre ciclos econômicos. A fra-

9 Choques exógenos no componente cíclico da produção representam variações em outros determinantes da volatilidade da produção que não foram explicitamente incluídos na análise VAR. 10 Esses resultados podem ser obtidos mediante solicitação aos autores. 


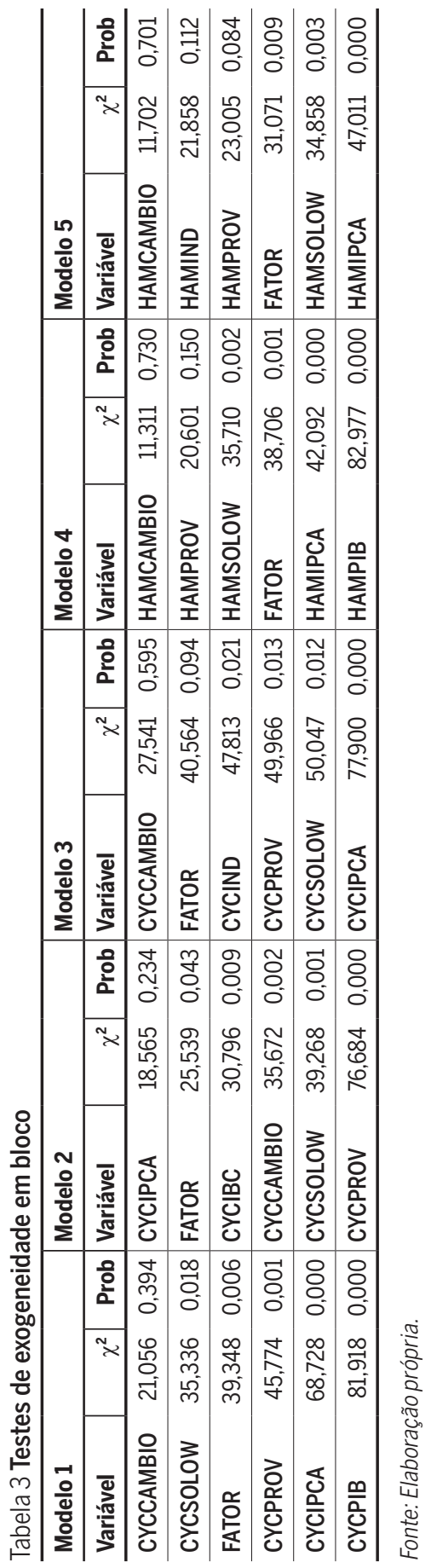


gilidade do sistema financeiro e o nível de preços tendem a declinar nos primeiros meses após o choque, refletindo a estabilidade proporcionada pelo desempenho econômico favorável.

A relação robusta entre fragilidade do sistema financeiro e desempenho macroeconômico no Brasil é semelhante aos resultados encontrados em Tiryaki et al. (2017). A resposta de CYCPROV a choques exógenos no componente cíclico da produção é estatisticamente significante em todos os modelos, embora com magnitude mais pronunciada nos modelos 1, 2 e 4. Já a resposta de CYCIPCA somente é estatisticamente relevante quando o componente cíclico do PIB é utilizado como indicador de volatilidade macroeconômica. A volatilidade cambial e o resíduo de Solow, por sua vez, não apresentam respostas estatisticamente significantes aos choques na produção.

Figura 5 Funções de resposta a impulsos generalizados: produção e fragilidade fiscal

\section{Modelo 1}

\section{a) Resposta de FATOR a impulsos em CYCPIB}

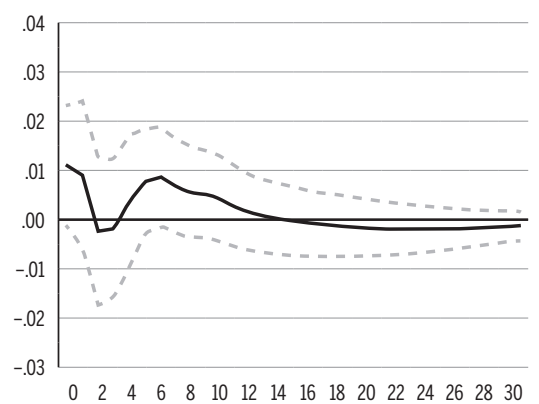

\section{Modelo 2}

\section{a) Resposta de FATOR a impulsos em CYCBC}

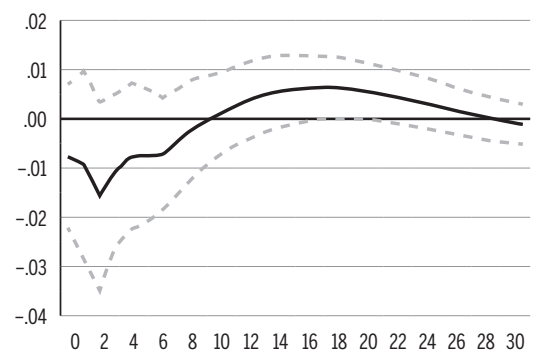

\section{b) Resposta de CYCPIB a impulsos em FATOR}

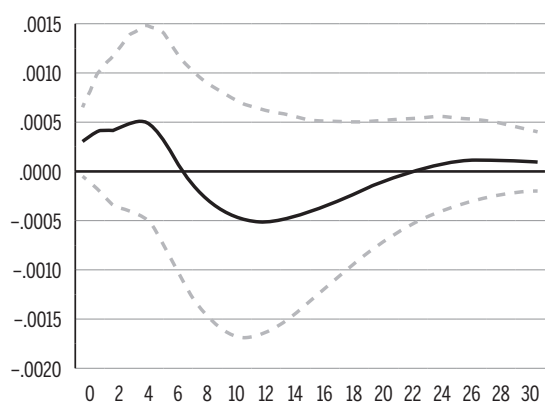

\section{b) Resposta de CYCBC a impulsos em FATOR}

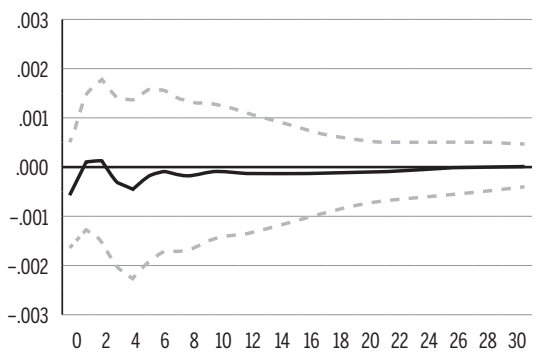




\section{Modelo 3}

\section{a) Resposta de FATOR a impulsos em CYCIND}

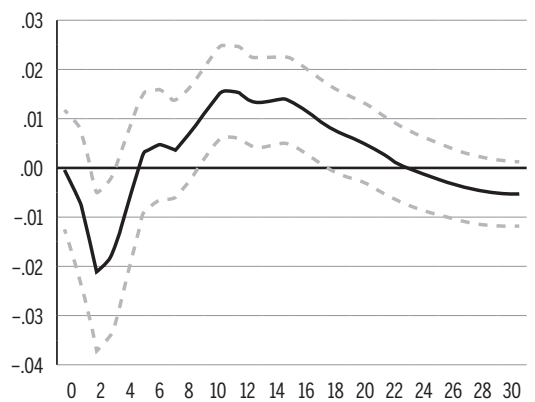

\section{Modelo 4}

\section{a) Resposta de FATOR a impulsos em HAMPIB}

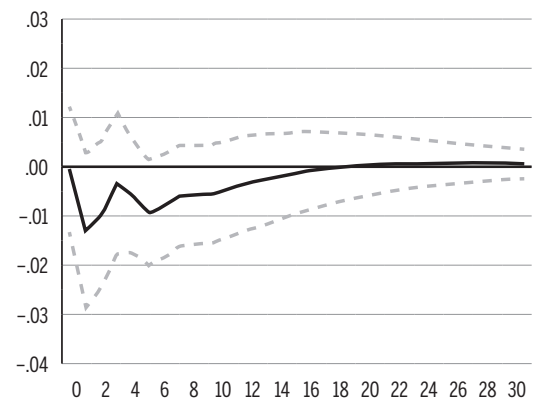

\section{Modelo 5}

\section{a) Resposta de FATOR a impulsos em HAMIND}

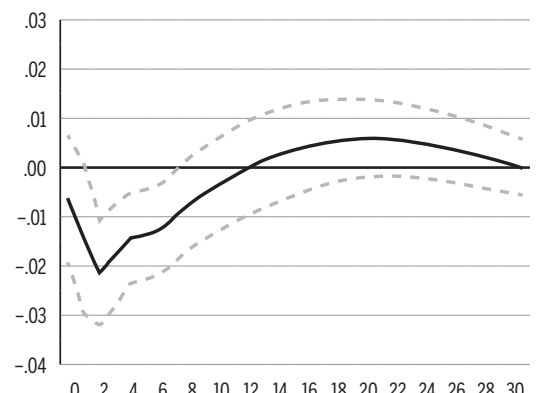

Fonte: Elaboração própria.

Nota: Respostas a um desvio padrão generalizado ( \pm 2 erros padrão).

\section{b) Resposta de CYCIND a impulsos em FATOR}

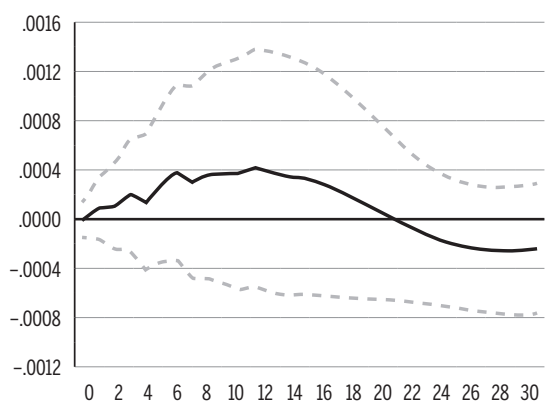

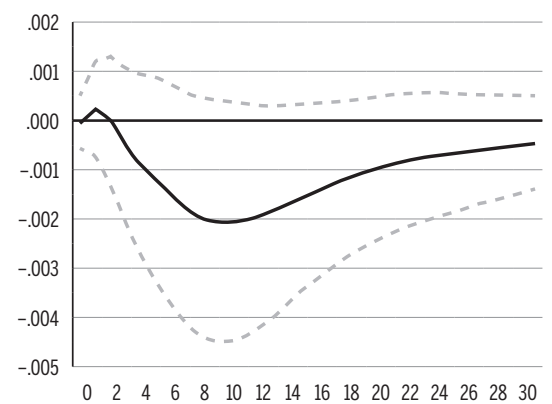

b) Resposta de HAMIND a impulsos em FATOR

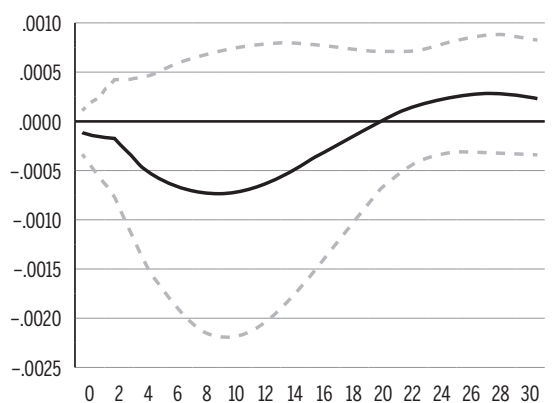


Figura 6 Funções de resposta a impulsos generalizados: choques na produção e desempenho de variáveis macroeconômicas

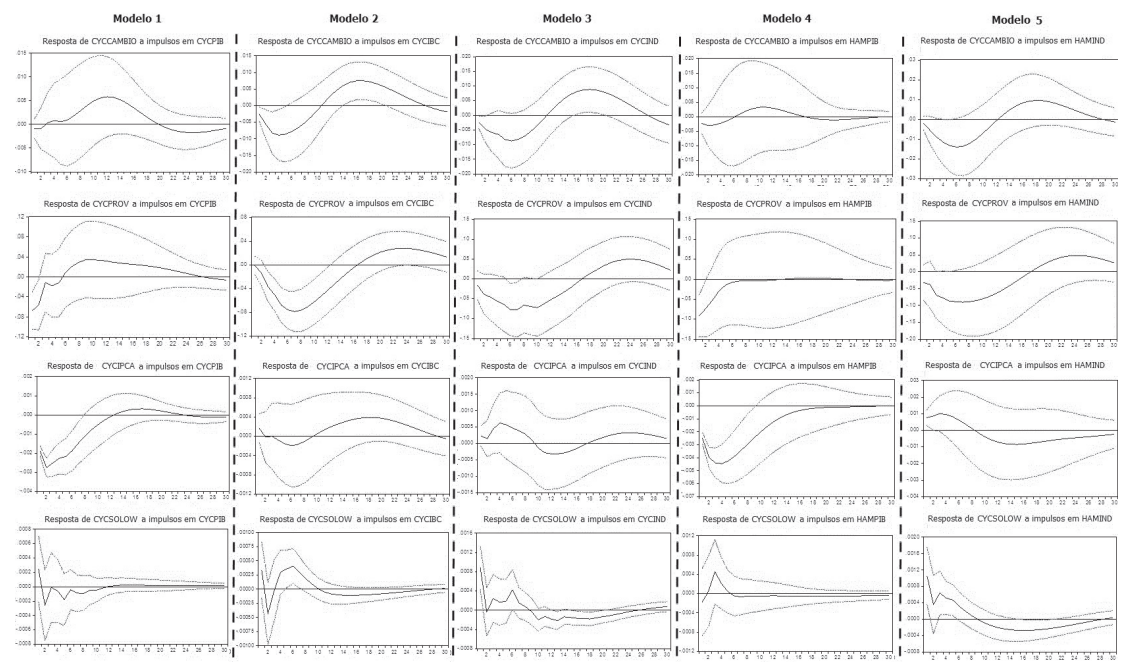

Fonte: Elaboração própria.

Nota: Respostas a um desvio padrão generalizado ( \pm 2 erros padrão).

Analisando os resultados de decomposição da variância apresentados na Tabela 4, observa-se que a variância do indicador de fragilidade fiscal é explicada principalmente pelas defasagens da própria variável. Ademais, verifica-se que a volatilidade na produção e, em menor grau, a volatilidade cambial também são relevantes, particularmente em um horizonte temporal mais longo. Os reflexos de choques na produção e na volatilidade cambial são observados com uma defasagem média de 12 meses e explicam entre $7 \%$ a $20 \%$ da variância em FATOR, a depender do modelo estimado.

Tabela 4 Decomposição de variância de FATOR, em \%

\begin{tabular}{|c|c|c|c|c|c|c|c|}
\hline \multicolumn{8}{|c|}{ Modelo 1} \\
\hline Mês & S.E. & CYCCAMBIO & CYCSOLOW & FATOR & CYCPROV & CYCIPCA & CYCPIB \\
\hline 1 & 0,017 & 0,212 & 0,849 & 98,939 & 0,000 & 0,000 & 0,000 \\
\hline 6 & 0,080 & 2,526 & 1,172 & 90,825 & 0,028 & 1,460 & 3,989 \\
\hline 12 & 0,088 & 4,169 & 1,793 & 79,668 & 0,064 & 2,506 & 11,802 \\
\hline 18 & 0,091 & 4,543 & 1,820 & 75,849 & 0,456 & 3,983 & 13,350 \\
\hline 24 & 0,091 & 5,672 & 1,810 & 74,469 & 0,686 & 4,228 & 13,136 \\
\hline
\end{tabular}


Tabela 4 (continuação)

\begin{tabular}{|c|c|c|c|c|c|c|c|}
\hline \multicolumn{8}{|c|}{ Modelo 2} \\
\hline Mês & S.E. & CYCIPCA & FATOR & CYCIBC & CYCСАMBIO & CYCSOLOW & CYCPROV \\
\hline 1 & 0,002 & 0,295 & 99,705 & 0,000 & 0,000 & 0,000 & 0,000 \\
\hline 6 & 0,007 & 2,747 & 90,343 & 1,726 & 3,215 & 0,342 & 1,626 \\
\hline 12 & 0,007 & 2,976 & 87,136 & 2,068 & 4,672 & 0,463 & 2,685 \\
\hline 18 & 0,008 & 2,998 & 85,140 & 3,047 & 4,690 & 0,477 & 3,648 \\
\hline 24 & 0,008 & 3,469 & 83,486 & 3,759 & 5,143 & 0,471 & 3,672 \\
\hline \multicolumn{8}{|c|}{ Modelo 3} \\
\hline Mês & S.E. & CYCCAMBIO & FATOR & CYCIND & CYCPROV & CYCSOLOW & CYCIPCA \\
\hline 1 & 0,017 & 0,039 & 99,961 & 0,000 & 0,000 & 0,000 & 0,000 \\
\hline 6 & 0,078 & 2,353 & 91,626 & 5,172 & 0,290 & 0,205 & 0,354 \\
\hline 12 & 0,083 & 3,669 & 83,671 & 9,350 & 0,634 & 0,640 & 2,035 \\
\hline 18 & 0,088 & 4,027 & 78,654 & 13,347 & 0,942 & 0,623 & 2,406 \\
\hline 24 & 0,091 & 6,071 & 76,071 & 13,177 & 1,239 & 0,622 & 2,820 \\
\hline \multicolumn{8}{|c|}{ Modelo 4} \\
\hline Mês & S.E. & HAMCAMBIO & HAMPROV & HAMSOLOW & FATOR & HAMIPCA & HAMPIB \\
\hline 1 & 0,028 & 0,836 & 0,281 & 0,190 & 98,693 & 0,000 & 0,000 \\
\hline 6 & 0,131 & 3,908 & 1,842 & 0,729 & 83,625 & 1,956 & 7,940 \\
\hline 12 & 0,143 & 10,302 & 2,775 & 0,694 & 76,367 & 2,347 & 7,514 \\
\hline 18 & 0,148 & 11,811 & 2,753 & 0,744 & 74,050 & 3,024 & 7,619 \\
\hline 24 & 0,148 & 11,840 & 2,915 & 0,844 & 73,254 & 3,354 & 7,793 \\
\hline \multicolumn{8}{|c|}{ Modelo 5} \\
\hline Mês & S.E. & HAMCAMBIO & HAMIND & HAMPROV & FATOR & HAMSOLOW & HAMIPCA \\
\hline 1 & 0,028 & 0,441 & 0,324 & 0,241 & 98,994 & 0,000 & 0,000 \\
\hline 6 & 0,129 & 2,157 & 7,714 & 1,325 & 88,158 & 0,320 & 0,325 \\
\hline 12 & 0,140 & 8,380 & 8,260 & 2,065 & 79,632 & 0,482 & 1,181 \\
\hline 18 & 0,147 & 10,562 & 8,470 & 2,107 & 76,484 & 0,466 & 1,910 \\
\hline 24 & 0,149 & 11,349 & 9,082 & 2,403 & 74,700 & 0,458 & 2,008 \\
\hline
\end{tabular}

Fonte: Elaboração própria.

Nota: Decomposição por Cholesky com ordenamento conforme indicado na Tabela 4.

Choques na volatilidade cambial são os principais determinantes da variância das demais variáveis endógenas dos modelos estimados, com exceção do resíduo de Solow. A importância de choques na taxa de câmbio para a estabilidade macroeconômica já havia sido documentada por Almeida et al. (2012) e Munhoz (2013). Na Figura 7, observa-se que uma 
maior volatilidade cambial desaquece a economia, aumenta o nível de preços e compromete a estabilidade do sistema financeiro em todos os modelos estimados. Ou seja, a relevância da volatilidade cambial para os ciclos econômicos no Brasil é um resultado robusto, pois independe do indicador utilizado como proxy de volatilidade macroeconômica e do filtro empregado para remover o componente cíclico das variáveis.

Figura 7 Volatilidade cambial e desempenho macroeconômico

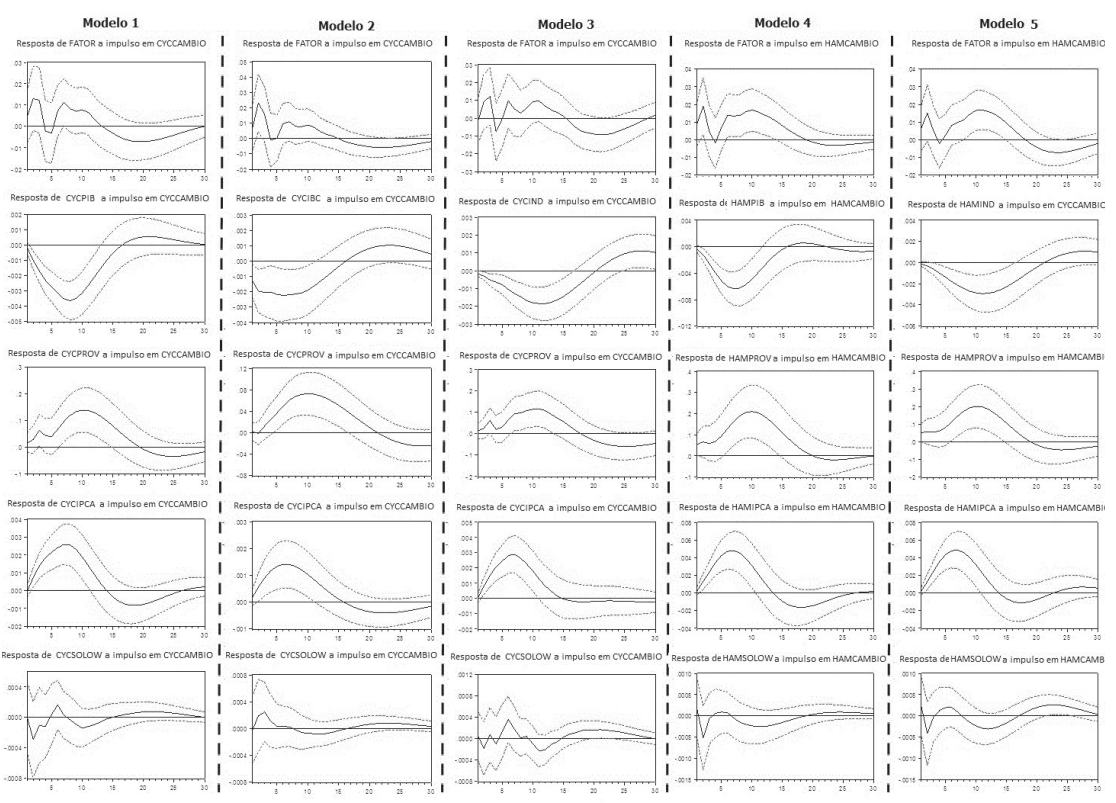

Fonte: Elaboração própria.

Nota: Respostas a um desvio padrão generalizado (ffI 2 erros padrão).

\section{Conclusões}

Processos recessivos severos geram perdas de produção e emprego não somente no curto prazo, mas podem comprometer o desempenho de longo prazo de um país. Políticas macroeconômicas são utilizadas para promover a estabilidade dos ciclos econômicos e, embora haja um menor questionamento quanto à importância das intervenções monetárias, a efetividade do uso de política fiscal como instrumento estabilizador ainda é controverso. 
Este trabalho derivou um indicador de fragilidade fiscal para o Brasil e, com a estimação de modelos VAR, verificou se expansões da atividade econômica são acompanhadas de maior fragilidade fiscal, como é comum em países emergentes. $O$ método de fator dinâmico permitiu reunir informações de séries temporais da contabilidade fiscal e identificar um fator latente único que determina o comportamento conjunto dessas variáveis. Identificar um indicador de fragilidade robusto permite seu uso em inferências, possibilita realizar previsões de desempenho fiscal e estimar impactos de variações na fragilidade fiscal sobre outras variáveis macroeconômicas.

Os resultados mostraram que a fragilidade fiscal declina em resposta a choques exógenos positivos na produção, indicando um comportamento contracíclico na conduta de política fiscal no Brasil. No entanto, esse resultado não é robusto à especificação do modelo: a depender do indicador de volatilidade da produção ou do filtro empregado para extrair o componente cíclico das séries temporais, a reação do índice de fragilidade fiscal pode não ser estatisticamente relevante. Salienta-se, contudo, que alguns estudos corroboram essa conclusão ao mostrarem que o comportamento do multiplicador fiscal no Brasil reflete um caráter contracíclico da política fiscal, e que a deterioração mais recente das contas públicas é resultado do desaquecimento econômico (Pires, 2014; Oreiro, 2017).

A análise empírica também demonstrou que choques exógenos na fragilidade fiscal não geram respostas estatisticamente significantes das variáveis macroeconômicas, uma indicação que a deterioração das contas públicas per se não compromete o desempenho da economia. É importante, portanto, identificar as reais fontes de instabilidade macroeconômica de curto prazo que afetam o desempenho fiscal ao desaquecer a economia.

Nesse sentido, a volatilidade cambial surge como um importante vetor de instabilidade macroeconômica. Os resultados empíricos mostraram que choques cambiais têm um impacto significativo sobre todas as variáveis endógenas, à exceção do resíduo de Solow. Um aumento na volatilidade cambial reduz a produção, eleva preços e aumenta as provisões para perdas com crédito. Esse conjunto de fatores eleva a fragilidade fiscal ao reduzir a arrecadação do governo e ao elevar o endividamento público, em razão do impacto do IPCA e da Selic sobre a dívida pública. 


\section{Referências}

AIYAGARI, R.; CHRISTIANO, L.; EICHENBAUM, M. The output, employment and interest rate effects of government consumption. Journal of Monetary Economics, v. 30, p. 73-86, 1992.

AKERLOF, G. A.; BLANCHARD, O.; ROMER, D.; STIGLITZ, J. E. (Ed.). What have we learned? Macroeconomic policy after the crisis. Boston: MIT Press, 2014.

ALESINA, A.; TABELLINI, G. Why is fiscal policy often procyclical? NBER Working Paper, n. $11.600,2005$.

ALESINA, A. Fiscal policy after the great recession. Atlantic Economic Journal, v. 40, n. 4, p. 429-435, 2012.

ALMEIDA, G.; ALVES, P.; LIMA, E. Impactos dos choques na política monetária e no câmbio do Brasil: um modelo de autorregressão vetorial estrutural aumentada por fatores dinâmicos. IPEA. Texto para discussão, n. 1.711, 2012.

ATHAYDE, D.; VIANNA, A. Dívida pública brasileira: uma análise comparativa dos três principais indicadores de esforço fiscal do governo. Nova Economia, v. 25, n. 2, p. 403-420, 2015.

ARUOBA, S. B.; DIEBOLD, F. X.; SCOTTI, C. Real-time measurement of business conditions. Journal of Business \& Economic Statistics, v. 27, p. 417-427, 2009.

AUERBACH, A. J. The fall and rise of Keynesian fiscal policy. Asian Economic Policy Review, v. 7, p. 157-175, 2012.

AUERBACH, A. J.; GORODNICHENKO, Y. Measuring the output responses to fiscal policy. American Economic Journal: Economic Policy, v. 4, n. 2, p. 1-27, 2012.

BACKUS, David K.; KEHOE, P. J.; KYDLAND, F. E. International real business cycles. Journal of Political Economy, v. 100, n. 4, p. 745-775, 1992.

BANCO CENTRAL DO BRASIL (BACEN). Séries temporais. Brasília: BACEN, 2019. Disponível em: <https://www3.bcb.gov.br/sgspub/localizarseries/localizarSeries.do?method= prepararTelaLocalizarSeries>. Acesso em: 14 maio 2019.

BASHAR, O.; BHATTACHARYA, P. S.; WOHAR, M. E. The cyclicality of fiscal policy: New evidence from unobserved components approach. Journal of Macroeconomics, v. 53, p. 222234, 2017.

BAXTER, M.; KING, R. G. Measuring business cycles: approximate band-pass filters for economic time series. Review of Economics and Statistics, v. 81, n. 4, p. 575-593, 1999.

BOIANOVSKY, M. The IS-LM model and the liquidity trap concept: From Hicks to Krugman. History of Political Economy, v. 36, n. 5, p. 92-126, 2004.

CABALLERO, R. J.; KRISHNAMURTHY, A. Fiscal policy and financial depth. NBER Working Paper, n. 10.532, 2004.

CAVALCANTI, M.; SILVA, NC. Dívida pública, política fiscal e nível de atividade: uma abordagem VAR para o Brasil no período 1995-2008. Economia Aplicada, v. 14, n. 4, p. 391-418, 2010.

CHRISTIANO, L.; FITZGERALD, T. The band pass filter. International Economic Review, v. 44, 
2003, p. 435-465.

CHRISTIANO, L.; EICHENBAUM, M.; REBELO, S. When is the government spending multiplier large? Journal of Political Economy, v. 119, p. 78-121, 2011.

COGAN, J. F.; CWIK, T.; TAYLOR, J. B.; WIELAND, V. New Keynesian versus Old Keynesian government spending multipliers. Journal of Economic Dynamics and Control, v. 34, p. 281-295, 2010.

COMITÊ DE DATAÇÃO DOS CICLOS ECONÔMICOS (CODACE). Comunicado de Datação de Ciclos Mensais Brasileiros - Out./2017. Rio de Janeiro: Fundação Getulio Vargas, 2017. Disponível em: <http://portalibre.fgv.br/main.jsp?lumChannelId=4028808126B9BC4C01 26BEA1755C6C93>. Acesso em: 25 jan. 2018.

EGGERTSSON, G. B. What fiscal policy is effective at zero interest rates? NBER Macroeconomics Annual, v. 25, n. 1, p. 59-112, 2011.

ELLERY, Roberto. Desafios para o cálculo da produtividade total dos fatores. In: DE NEGRI, F.; Cavalcanti, R. Produtividade no Brasil: desempenho e determinantes. Brasília: IPEA, 2014.

FERRARI-FILHO, F.; TERRA, F. H. B.; CONCEIÇÃO, O. A. C. The financial fragility hypothesis applied to the public sector: an analysis for Brazil's economy from 2000 to 2008. Journal of Post Keynesian Economics, v. 33, n. 1, p. 151-168, 2010.

FERRARI-FILHO, F; TERRA, F. H. B. A hipótese de fragilidade financeira aplicada ao setor público: uma análise para a economia brasileira no período 2000-2009. Revista Economia, v. 12, n. 3, p. 497-516, 2011.

FERRARI-FILHO, F; TERRA, F. H. B. Keynes' Interventionist-Reformist Economic Policies. Investigación Económica, p. 17-41, 2012.

FERREIRA DA SILVA, G. The impact of financial system development on business cycles volatility: cross-country evidence. Journal of Macroeconomics, v. 24, n. 2, p. 233-253, 2002.

FRANKEL, J. A.; VEGH, C. A.; VULETIN, G. On graduation from fiscal procyclicality. Journal of Development Economics, v. 100, n. 1, p. 32-47, 2013.

GADELHA, S. R. de B.; DIVINO, J. A. Uma análise da ciclicidade da política fiscal brasileira. Estudos Econômicos, v. 43, n. 4, p. 711-743, 2013.

GALI, J. J.; LÓPEZ-SALIDO, D.; VALLÉS, J. Understanding the effects of government spending on consumption. Journal of the European Economic Association, v. 5, p. 227-270, 2007.

GAVIN, M.; PEROTTI, R. Fiscal policy in Latin America. NBER Macroeconomics Annual, v. 12, p. 11-61, 1997.

GEWEKE, J. The dynamic factor analysis of economic time series models. In: Latent Variables in Socioeconomic Models, AIGNER, D. J.; GOLDBERGER, A. S. (Ed.). Amsterdam: North-Holland, 1977. p. 365-383.

GOBETTI, S. W.; ORAIR, R. O. Política fiscal em perspectiva: o ciclo de 16 anos (1999-2014). Revista de Economia Contemporânea, v. 19, n. 3, p. 417-447, 2015.

GOBETTI, S. W.; ORAIR, O. Resultado primário e contabilidade criativa: Reconstruindo as estatísticas fiscais "acima da linha" do governo geral. IPEA Texto para Discussão, n. 2288, 2017.

GOBETTI, S. W.; ALMEIDA, V. L. Uma radiografia do gasto público federal entre 2001 e 
2015. IPEA. Texto para discussão, n. 2.191, 2016.

HAMILTON, J. D. Why you should never use the Hodrick-Prescott filter. NBER Working Paper, n. 23.429, 2017.

HEMMING, R.; KELL, M.; MAHFOUZ, S. The effectiveness of fiscal policy in stimulating economic activity - A Review of the Literature. IMF Working Paper 02/208, 2002.

HODRICK, R. J.; PRESCOTT, E. C. Postwar US business cycles: an empirical investigation. Journal of Money, Credit, and Banking, p. 1-16, 1997.

INSTITUTO BRASILEIRO DE GEOGRAFIA E ESTATÍSTICA (IBGE). Séries Históricas e Estatísticas. Brasília: IBGE, 2019. Disponível em: <https://seriesestatisticas.ibge.gov.br/> Acesso em: 15 maio 2019.

INTERNATIONAL MONETARY FUND (IMF). Quarterly national accounts manual. Washington: IMF, 2017.

KAMINSKI, G.; REINHART, C.; VEGH, C. When it rains it pours: Procyclical capital flows and macroeconomic policies in Mark Gertler and Kenneth Rogoff (Ed.). NBER Macroeconomic Annual 2004. Cambridge, MA: MIT Press, 2004.

KARRAS, G; SONG, F. Sources of business-cycle volatility: An exploratory study on a sample of OECD countries. Journal of Macroeconomics, v. 18, n. 4, p. 621-637, 1996.

KEYNES, J. M. A teoria geral do emprego, do juro e da moeda. São Paulo: Atlas, 1992.

LÜTKEPOHL, H. New introduction to multiple time series analysis. Springer Science \& Business Media, 2005.

MANKIW, N. G; SUMMERS, L. H. Do long-term interest rates overreact to short-term interest rates? NBER Working Paper, n. 1345, 1984.

MENDONÇA, M. J. C. de; SANTOS, C. H. M. dos; SACHSIDA, A. Revisitando a função de reação fiscal no Brasil pós-Real: uma abordagem de mudanças de regime. Estudos Econômicos, v. 39, n. 4, p. 873-894, 2009.

MINSKY, H. P. Stabilizing an unstable economy. New Jersey: Yale University Press, 1986.

MOURA, B. A.; TIRYAKI, G.F. Fragilidade financeira do setor público e os ciclos econômicos. Revista Desenbahia, v. 13, n. 22, p. 53-80, 2016.

MUNHOZ, V.C.V. Vulnerabilidade externa e controle de capitais no Brasil: uma análise das inter-relações entre câmbio, fluxos de capitais, IOF, juros e risco-país. Nova Economia, v. 23, n. 2, p. 371-402, 2013.

NICKEL, C.; TUDYKA, A. Fiscal Stimulus in Times of High Debt: Reconsidering multipliers and twin deficits. Journal of Money, Credit and Banking, v. 46, p. 1.313-1.344, 2014.

OLIVEIRA, G. C.; VAZQUEZ, D. A.; WOLF, P. J. W. Debt and borrowing requirements of the Brazilian public sector (1995-2016): An assessment of the post-Real period. Revista de Economia Contemporânea, v. 21, n. 3, 2017.

ORAIR, R. O. Desonerações em alta com rigidez da carga tributária: o que explica o paradoxo do decênio 2005-2014? Texto para Discussão - IPEA, n. 2117, 2015.

OREIRO, J. L. A grande recessão brasileira: diagnóstico e uma agenda de política econômica. Estudos Avançados, v. 31, n. 89, p. 75-88, 2017. 
PESARAN, H. H; SHIN, Y. Generalized impulse response analysis in linear multivariate models. Economics Letters, v. 58, n. 1, p. 17-29, 1998.

PIRES, M. C. de C. Política fiscal e ciclos econômicos no Brasil. Economia Aplicada, v. 18, n. 1, p. 69-90, 2014.

QUAH, D.; SARGENT, T. J. A Dynamic index model for large cross sections. In: STOCK, J. H.; Watson, M. W. (Ed.). Business Cycles, indicators, and forecasting. Chicago: University of Chicago Press, 285-310, 1993.

RAMEY, V. A. Can government purchases stimulate the economy? Journal of Economic Literature, v. 49, n. 3, p. 673-685, 2011.

SCHETTINI, B. P. Determinação dos superávits do governo central brasileiro: influência da política monetária na ótica de regressões de limiar. Estudos Econômicos, v. 44, n. 2, p. 241 275, 2014.

SCHULER, Y. S. On the cyclical properties of Hamilton's regression filter. Bundesbank Discussion Paper, n. 3, 2018.

SMETS, F.; WOUTERS, R. Shocks and frictions in U.S. business cycles: A Bayesian DSGE approach. American Economic Review, v. 97, p. 586-606, 2007.

STOCK, J. H.; WATSON, M. W. Dynamic factor models, factor-augmented vector autoregressions, and structural vector autoregressions in macroeconomics. Handbook of Macroeconomics. Elsevier, p. 415-525, 2016.

TALVI, E.; VEGH, C. Tax base variability and procyclicality of fiscal policy. Journal of Development Economics, forthcoming, 2005.

TERRA, F. H. B; FERRARI-FILHO, F. Índice de fragilidade financeira do setor público revisitado: uma análise para o governo federal brasileiro no período 2000-2016. In: CONGRESSO BRASILEIRO DE HISTÓRIA ECONÔMICA, XII., Niterói, 2017.

TIRYAKI, G. F.; GAVAZZA, I. O.; ANDRADE, C. M.; SANTOS, A. L. M. Ciclos de crédito, inadimplência e as flutuações econômicas no Brasil. Revista de Economia Contemporânea, v. 21, n. 1, 2017.

TORNELL, A.; LANE, P. R. The voracity effect. American Economic Review, v. 89, n. 1, p. 22-46, 1999.

\section{Sobre os autores}

Bruno Alves Moura - ex.bruno@gmail.com

Economics Department, Universität Siegen, Siegen, Alemanha.

ORCID: https://orcid.org/0000-0003-3194-6678.

Gisele Ferreira Tiryaki-gtiryaki@ufba.br

Faculdade de Economia, Universidade Federal da Bahia, Salvador, Bahia, Brasil.

ORCID: https://orcid.org/0000-0002-2608-5378.

Diego Nunes Teixeira-diegont2@yahoo.com.br

Faculdade de Economia, Universidade Federal da Bahia, Salvador, Bahia, Brasil.

ORCID: https://orcid.org/0000-0002-9945-7902.

\section{Sobre 0 artigo}

Recebido em 14 de outubro de 2018. Aprovado em 06 de setembro de 2019. 